\title{
HIGH POWER ULTRASONIC \\ BOND STRENGTH EVALUATION
}

\author{
F. L. Becker
}

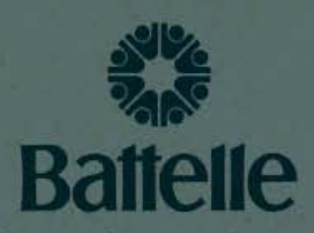

Pacific Northwest Laboratories

Richland, Washington 99352

OCTOBER 1973

Prepared for the U.S. Atomic Energy

Commission under Contract AT(45-1):1830 


\title{
NOTICE
}

The report was prepared as an account of work sponsored by the United States Government, Neither the United States nor the United States Atomic Energy Commission, nor any of their employees, nor any of their contractors, subcontractors, or their employees, makes any warranty, express or implied, or assumes any legal liability or responsibility for the accuracy, completeness or usefulness of any information, apparatus, product or process disclosed, or represents that its use would not infringe privately owned rights.

\author{
PACIFIC NORTHWEST LABORATORY \\ operated by \\ BATTELLE \\ for the \\ U.S. ATOMIC ENERGY COMMISSION \\ Under Contract AT(45-1)-1830
}

\author{
Printed in the United States of America \\ Available from \\ National Technical Information Service \\ U.S. Department of Commerce \\ 5285 Port Royal Road \\ Springfield, Virginia 22151
}

Price: Printed Copy \$4.00; Microfiche $\$ 0.95$ 
33679000622888

BNWL -1789

Special Distribution

HIGH POWER ULTRASONIC

BOND STRENGTH EVALUATION

\author{
By \\ F. L. Becker
}

October 1973

BATTELLE

PACIFIC NORTHWEST LABORATORIES

RICHLAND, WASHINGTON 


\section{CONTENTS}

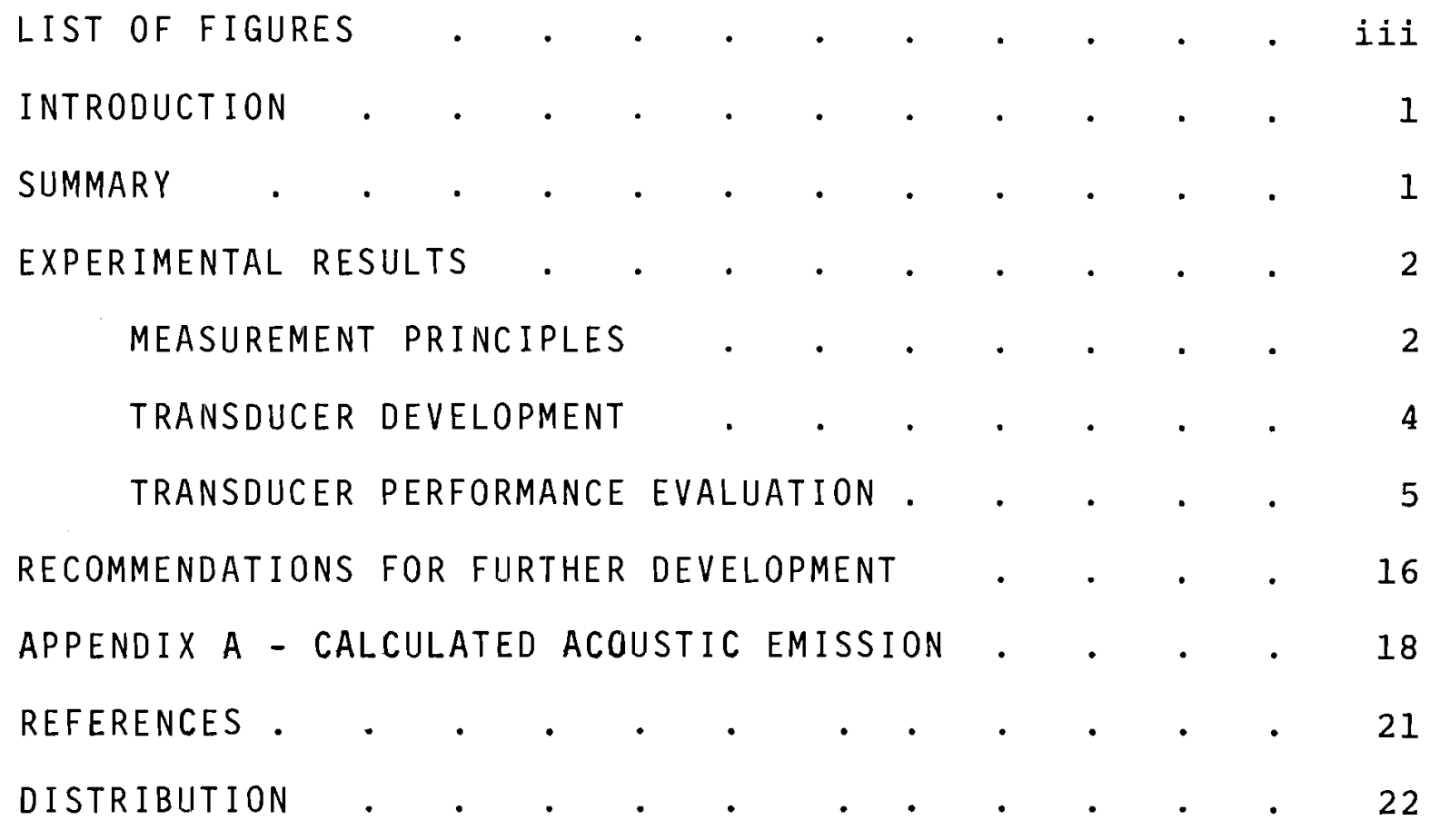




\section{LIST OF FIGURES}

1 System block diagram . . . . . . . . . . . . . . 3

2 Photograph of the three transducers; From left to right -

$1 \mathrm{MHz}, 3.75 \mathrm{in}$. radius; $300 \mathrm{kHz} 2.8 \mathrm{in}$. radius and

$1 \mathrm{MHz} 2 \mathrm{in}$. radius . . . . . . . . . . . . 6

3 Cross sectional sketch of the $300 \mathrm{kHz}$ transducer . . . . . 6

4 Results of high power insonification of a water film . . . . 7

5 Unbond produced by 1 . MHz ultrasound between two epoxy bonded glass microscope slides . . . . . . . . . . 9

6 Unbonds produced by $1 \mathrm{MHz}$ ultrasound between the layers of a stack of five epoxy bonded glass microscope slides . . . . . . . . . . . . . . . . 9

7 Forty $X$ mangification of an unbonded area

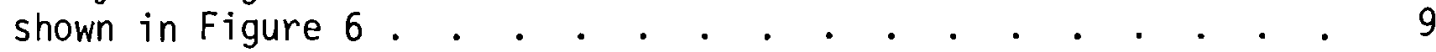

8 Fracture produced in $1 / 4$ inch plate glass by $300 \mathrm{kHz}$ ultrasound . . . . . . . . . . . . . 10

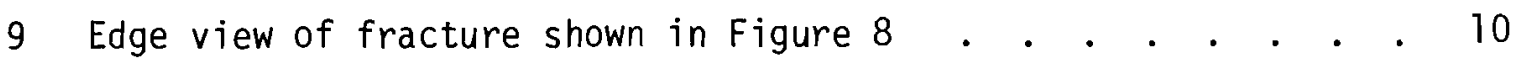

10 Fracture of fused quartz produced by $300 \mathrm{kHz}$ ultrasound . . . 11

11 Unbonds produced between a .002 in. copper, vapor deposited, film and the steel substrate by $300 \mathrm{kHz}$ ultrasound . . . . . . . . . . . . . 12

12 Forty $X$ enlargement of the central damage

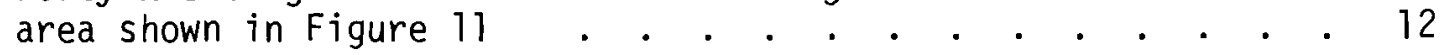

13 Vapor deposited Nickel film .002 in. thick on a glass substrate partially removed by insonification at $300 \mathrm{kHz}$

14 Pulse echo signal received by a $10 \mathrm{MHz}$ shear transducer mounted on two .250 gage blocks as shown in Figure 1. A) before and B) during insonification at $300 \mathrm{kHz}$. Clamping pressure was 1,000 psi . . . . . . 15

15 Same as Figure 14 except gage blocks are .250 and .800 in. transducer is $15 \mathrm{MHz}$ longitudinal and clamping pressure is 15,000 psi. A) before B) during and $C$ ) after insonification 


\title{
HIGH POWER ULTRASONIC \\ BOND STRENGTH EVALUATION
}

\author{
F. L. Becker
}

\section{INTRODUCTION}

Bond strength of diffusion and adhesive bonds has long remained one of the unsolved problems facing the materials testing industry. Many techniques are available for the detection of unbonds but these tend to become inaccurate when the unbonded surfaces are in intimate contact. Weak bonds in almost all cases cannot be distinguished from bonds which approach base material strengths. One must usually resort to destructive testing of samples cut from production parts to obtain bond strength information. This is not the most satisfactory method from a cost and reliability standpoint. The accuracy of this data is also in some doubt since the cutting procedure itself may disturb the bond and the residual stress pattern of the part.

The ultrasonic approach which we describe in this report has the potential of eliminating many of the limitations of existing bond testing techniques. The system is based on the use of high power ultrasonic waves to stress the bond interface with an acoustic pressure sufficient to break bonds of below minimum allowable strengths. Acceptable production parts may be $100 \%$ inspected with no detrimental affects.

This report describes the technique, equipment, and transducers developed for this test as we 11 as tests which indicate the feasibility of the method. Suggestions for further development are also included.

\section{SUMMARY}

This investigation has demonstrated the basic feasibility of using high power ultrasonic traveling waves to measure bond strength. Demonstrations were performed which indicated that bond strengths up to 14,000 psi could be tested with the equipment which was developed 
during this program. Further development and improvement of the system may yield considerably higher testing levels.

These tests were performed using a high power focused transducer with a steel focusing cone epoxy bonded to the sample. The tests included adhesive, simulated diffusion and thin vapor deposited film bond strength evaluations. Fractures in glass were also produced which indicate the power output of the transducer exceeds 14, 000 psi.

The advantages of this system of bond evaluation are compared with existing destructive tests. A suggested program for further development is also described.

\section{EXPERIMENTAL RESULTS}

\section{MEASUREMENT PRINCIPLES}

This technique for measuring bond strength is based on the use of high power ultrasonic waves to stress the bond interface to its breaking point. The stress or acoustic pressure generated by a traveling acoustic wave is given by

$$
P=-\rho c^{2} \varepsilon
$$

where $\rho$ is the density $c$ is the acoustic velocity and $\varepsilon$ is the strain. The strain is given by

$$
\varepsilon=\frac{\delta \xi}{\delta \chi}
$$

where $\xi$ is the displacement.

For a sinusoidal wave

$$
\xi=\xi_{0} \sin (\omega t-k x)
$$

and the peak strain is therefore $\varepsilon=-k \xi_{0}$ where $k$ is the wave number $\left(\frac{2 \pi}{\lambda}\right)$

$\omega$ is the angular frequency. Equation (1) can then also be defined as $p=\rho c \omega \xi$.

From Equ. (4) see that the pressure depends on the frequency and the displacement. Increasing $\omega$ generates higher pressures for a given displacement, however, a given pressure results in higher displacements at lower frequencies. We therefore must select the compromise frequency to generate sufficient pressure and displacement to break weak bonds. 
The initial goal of this program was to achieve the highest possible acoustic intensities using available materials and equipment. The basic equipment configuration is shown in Figure 1. A focused transducer is used to concentrate the available energy at the focal point, i.e., the bond line. A steel coupling cone bonded to the transducer element is used to couple the acoustic energy of the transducer into the bond sample. The transducer is driven by a $20 \mathrm{kw}$ Velonex pulser which produces a burst of electric pulses of variable width frequency and amplitude. The pulse width and frequency are adjusted to drive the transducer in its resonant mode to achieve maximum power output. A variable inductor is used for electrical tuning.

To detect the presence of an unbond created by high power ultrasound a separate high frequency transducer is used. This transducer may be a shear or longitudinal type and is placed directly below the focal point of the high power transducer. The unbond is detected by the relative amplitude of high frequency (10-20 MHz) ultrasonic pulses reflected from and transmitted through the bond line interface.

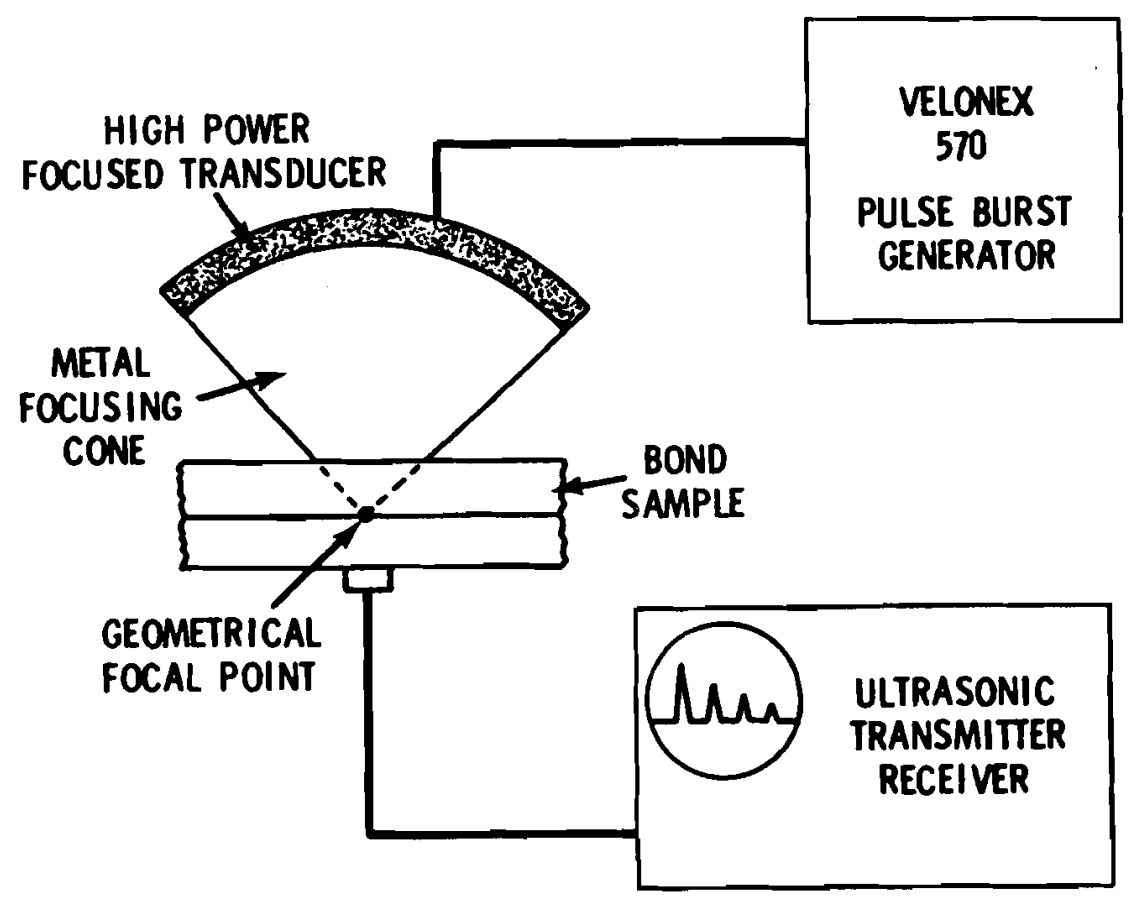

Figure 1. System Block Diagram 
The output of the power transducer is a sinewave burst approximately $200 \mathrm{usec}$ long with a burst repetition rate of $100 \mathrm{per} \mathrm{sec}$. The test requires only one to two seconds therefore limiting the total number of cycles to a ten thousand or less total cycles. This minimizes the effects of heat and fatigue which might otherwise damage serviceable parts.

\section{TRANSDUCER DEVELOPMENT}

The key element of this system is, of course, the transducer. The major criteria which must be considered in the design of this transducer are as follows:

1. The transducer material must have a high piezoelectric modulus $d_{33}$.

2. The focusing cone material should be selected to match the acoustic impedance of the transducer and the sample for maximum power transfer.

3. The focal distance and area of the transducer should be selected to give maximum power at the focal point.

4. The electrical impedance of the driving source should closely match that of the transducer. Each of these elements are discussed separately below.

The most likely candidate transducer material is the lead zirconate titanate (PZT) materials. Many different compensations of PZT are available with piezoelectric modulus $d_{33}$ ranging from 300 . to 585 . $10^{-2} \mathrm{~m} / \mathrm{v}$. The dynamic tensile strength must also exceed the expected service stresses of approximately 2,000 psi or more.

The material for the focusing cone must also be selected to match the acoustic impedance of the transducer material as well as the sample material. This will insure the maximum energy transfer to the bond line. A normal value of acoustic impedance of PZT is $28 . \times \frac{10^{6} \mathrm{~kg}}{\mathrm{~m}^{2} \mathrm{sec}}$.

Materials such as titanium and beryllium with impedances of 27 . and $23.5 \mathrm{kgm} / \mathrm{cm}^{2} \mathrm{sec} \times 10^{5}$ respectively would be an ideal match to the transducer. In most cases, however, a compromise between the transducer material and the test material must be selected. 
The acoustic power which can be generated at the focal point of a focused transducer depends on the transducer area $(A)$, focal length $(f)$ and wavelength $(\lambda)$ is given by (1)

$$
p=p_{0} \frac{A}{f \lambda} \text {. }
$$

Since the area increases as the second power of the radius or focal length we see that $P$ increases only as the first power of the radius. We are again faced with a compromise since the capacitance of the transducer increases as the square of the radius and thus limits our ability to drive the transducer. Increasing the frequency increases the focusing efficiency. Electrical impedance matching between the source and the transducer will maximize the power transfer and the transducer output.

The actual design of our transducers has been based on a compromise between the parameters listed above and the limitations of the materials and equipment available. Three transducers were fabricated using steel focusing cones and PZT transducer elements. The first and smallest was a 2 in. dia 2 in. focal length $1 \mathrm{MHz}$ unit which was used for the initial experiments. The other two larger units were a $1 \mathrm{MHz}$ unit using seven 2 in. dia $3.75 \mathrm{in}$. radius transducers and a $300 \mathrm{kHz} 2.8 \mathrm{in}$. radius hemispherical she11. The same basic design was used for each of the transducers. A photograph of the three units is shown in Figure 2. The $300 \mathrm{kHz}$ unit was used for most of the experiments and wi 11 be used as an example in the following description.

A cross section sketch of the $300 \mathrm{kHz}$ unit is shown in Figure 3 . The transducer element is $120^{\circ}$ of a $300 \mathrm{kHz} 6 \mathrm{in.} \mathrm{0.D.} \mathrm{hemisphere.} \mathrm{The} \mathrm{trans-}$ ducer is bonded to the focusing cone using an epoxy which has an approximate thickness of $.001 \mathrm{in}$. The focusing cone is terminated $.25 \mathrm{in}$. from the focal point. The ultrasonic power of the transducer would be focused on the surface of a 1/4 in. plate bonded to the focusing cone.

\section{TRANSDUCER PERFORMANCE EVALUAT ION}

The actual power output of our transducers have not as yet been measured. An estimate of the power capabilities of this transducer is calculated in Appendix $A$ at 17,580 psi at the focal point. 


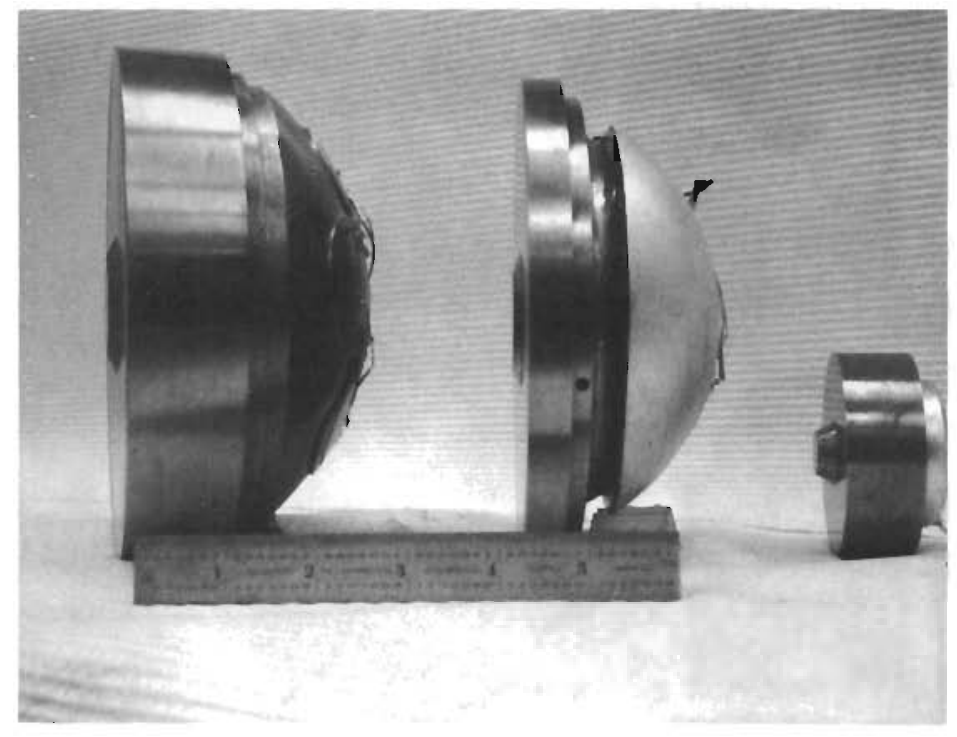

FIGURE 2. Photograph of the three transducers; From left to right $1 \mathrm{MHz}, 3.75$. radius; $300 \mathrm{kHz} 2.8 \mathrm{in}$. radius and $1 \mathrm{MHz} 2$ in. radius.

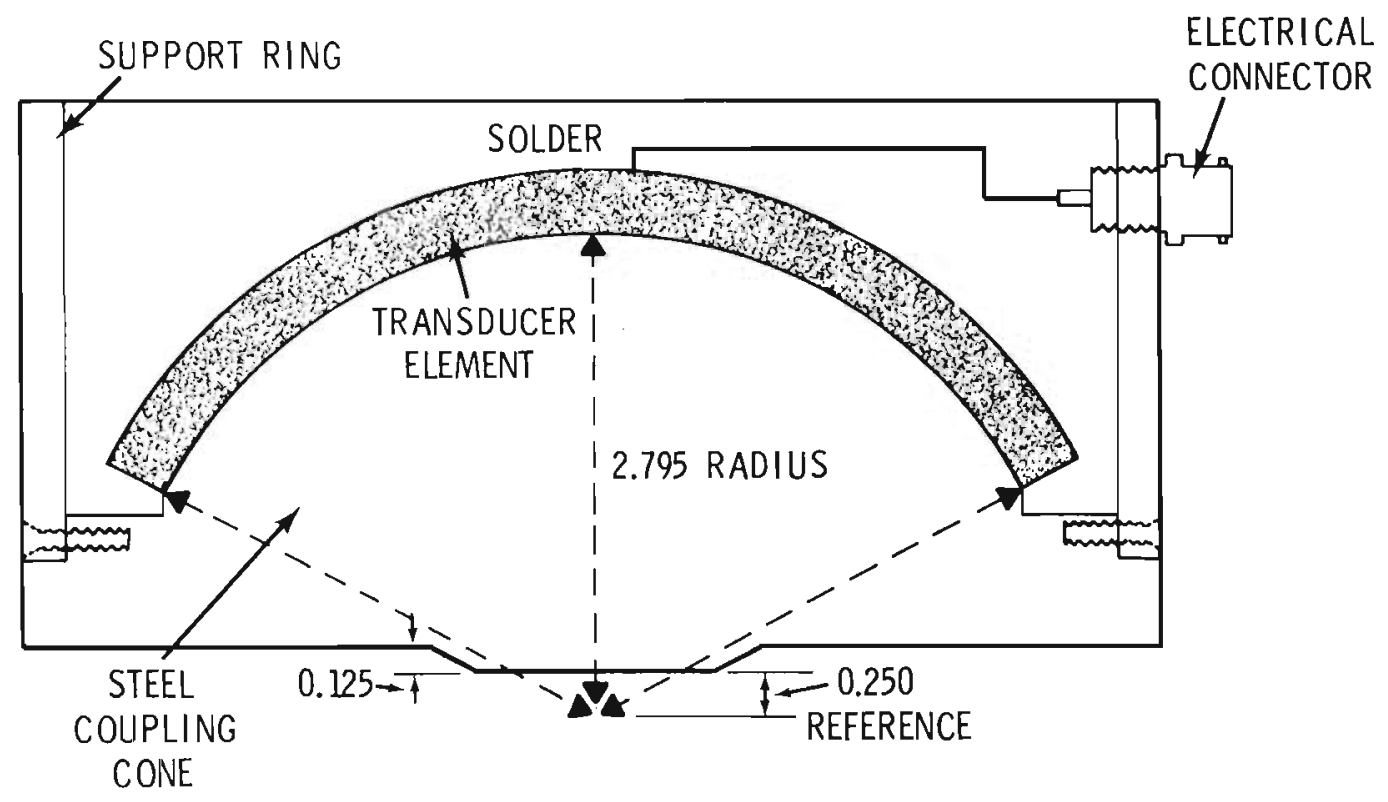

FIGURE 3. Cross sectional sketch of the $300 \mathrm{kHz}$ transducer. 
We have also performed many demonstrations to prove the capabilities of the system. There are, however, several sophisticated optical techniques ${ }^{(2,3)}$ available which are capable of measuring the actual transducer displacements at the focal point.

Most of our tests were performed using the $300 \mathrm{kHz}$ transducer and the 50 s output module of the Velonex pulser. A small parallel tuning inductor was also used to obtain maximum drive voltage. A maximum voltage of 1,250 volts measured at the transducer was obtained. A maximum burst length of $400 \mu \mathrm{sec}$ at a repetition rate of 300 per sec is available, however, most tests were performed at lengths of approximately $200 \mu \mathrm{sec}$ at 100 repetitions per second.

One of the most graphic, if not quantitative, demcnstrations was a thin film of water placed on the surface of a $1 / 4$ inch thick test plate bonded to the transducer. Figure 4 is a photograph of the phenomenon. A geyser of vapor and droplets is propelled from the plate surface with some of the droplets reaching a height of four to five feet above the transducer with the pulsed conditions described.

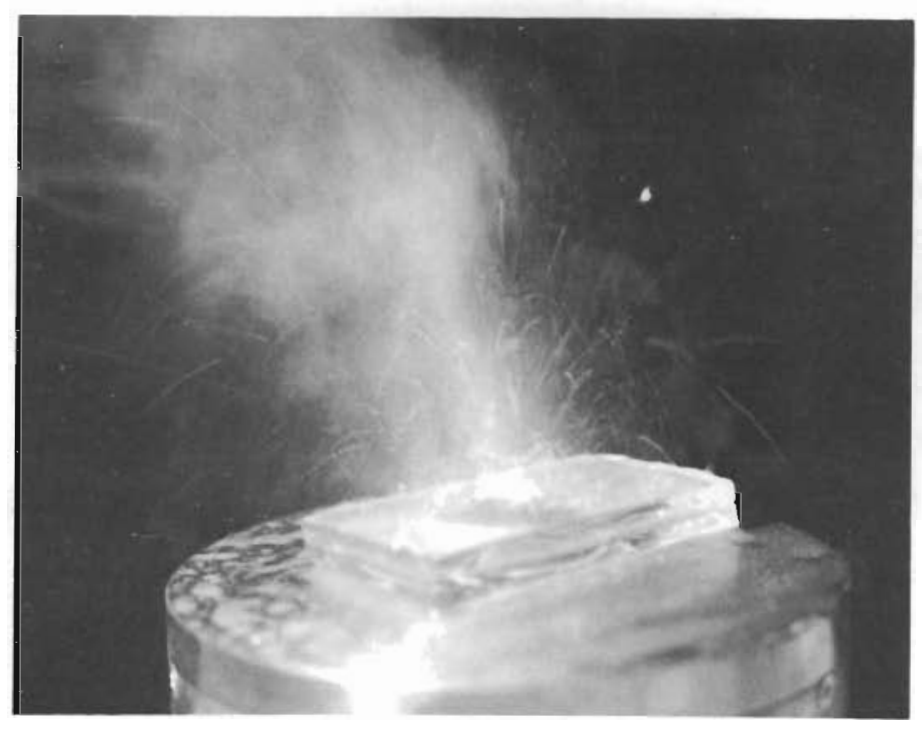

FIGURE 4. Results of high power insonification of a water film. 
Other more quantitative demonstrations were performed using adhesive bonds. In Figures 5 and 6 epoxy bonds between glass microscope slides were broken at relatively low power levels. In Figure 5 the central white area is an unbond between the two glass plates and was achieved using the smal1 $1 \mathrm{MHz}$ transducer. In Figure 6 unbonds occurred in the center and edges of a stack of five glass slides. The unbonds occurred at several different layers. Exposure times were kept short during these tests to prevent damage due to heat. A $40 \mathrm{x}$ micrograph of one of the disbond areas of Figure 6 is shown in Figure 7 showing the fracture pattern. Tensile tests on glass plates bonded with this epoxy indicated a tensile strength of 1,000 psi similar tests on steel plates indicated a strength of near 3,000 psi.

Of the demonstrations performed one of the most quantitative results was the fracture of glass samples. Figure 8 shows the fracture in a $1 / 4$ in. thick plate glass sample. The glass was bonded to a $1 / 4$ inch thick plate glass sample. The glass was bonded to a $1 / 4$ inch thick steel plate which was then bonded to the transducer. The fracture appeared almost instantaneously with the application of $80 \%$ of maximum power. Figure 9 is an edge on view of the same fracture. The diameter of the fracture at the interface is approximately 0.25 in. flaring out to approximately $1.25 \mathrm{in}$. at about $0.1 \mathrm{in}$. into the plate. This appears to be a combination of shear and tensile failu:e. This glass was tested in three point bending and found to have a strength of $14,000 \pm 3,000$ psi.

A fracture in fused quartz was also produced and is shown in Figure 10. This fracture appears to be a shear failure as it is approximately 45 degrees to the surface. The strength of fused quartz is estimated to between 10 and $20 \mathrm{kpsi}$. 


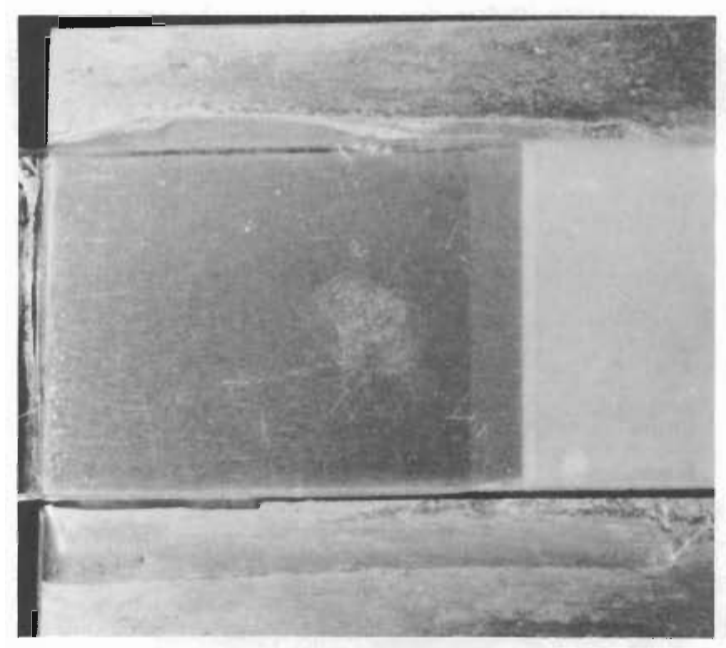

FIGURE 5. Unbond produced by 1. MHz ultrasound between two epoxy bonded glass microscope slides.

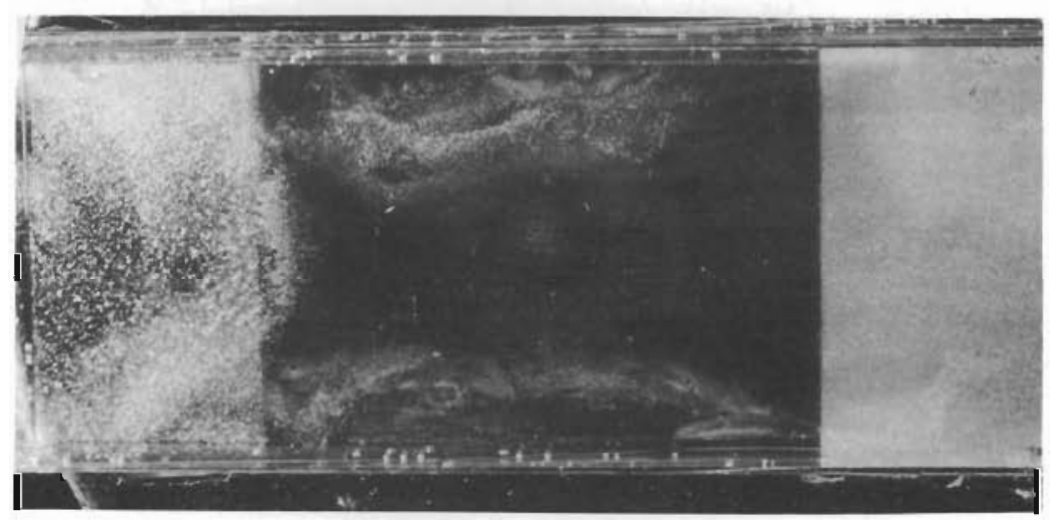

FIGURE 6. Unbonds produced by $1 \mathrm{MHz}$ ultrasound between the Tayers of a stack of five epoxy bonded glass microscope slides.

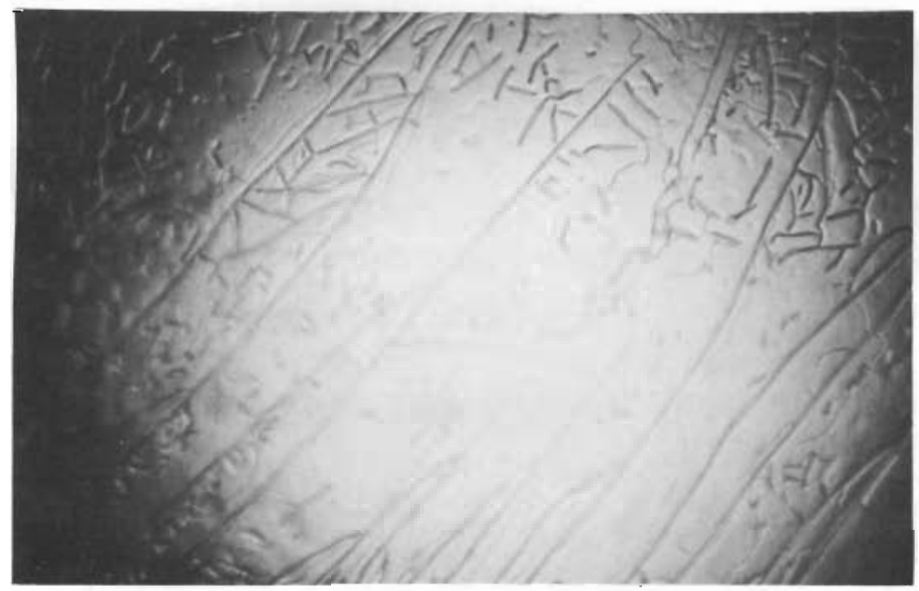

FIGURE 7. Forty $X$ magnification of an unbonded area shown in Figure 6. 


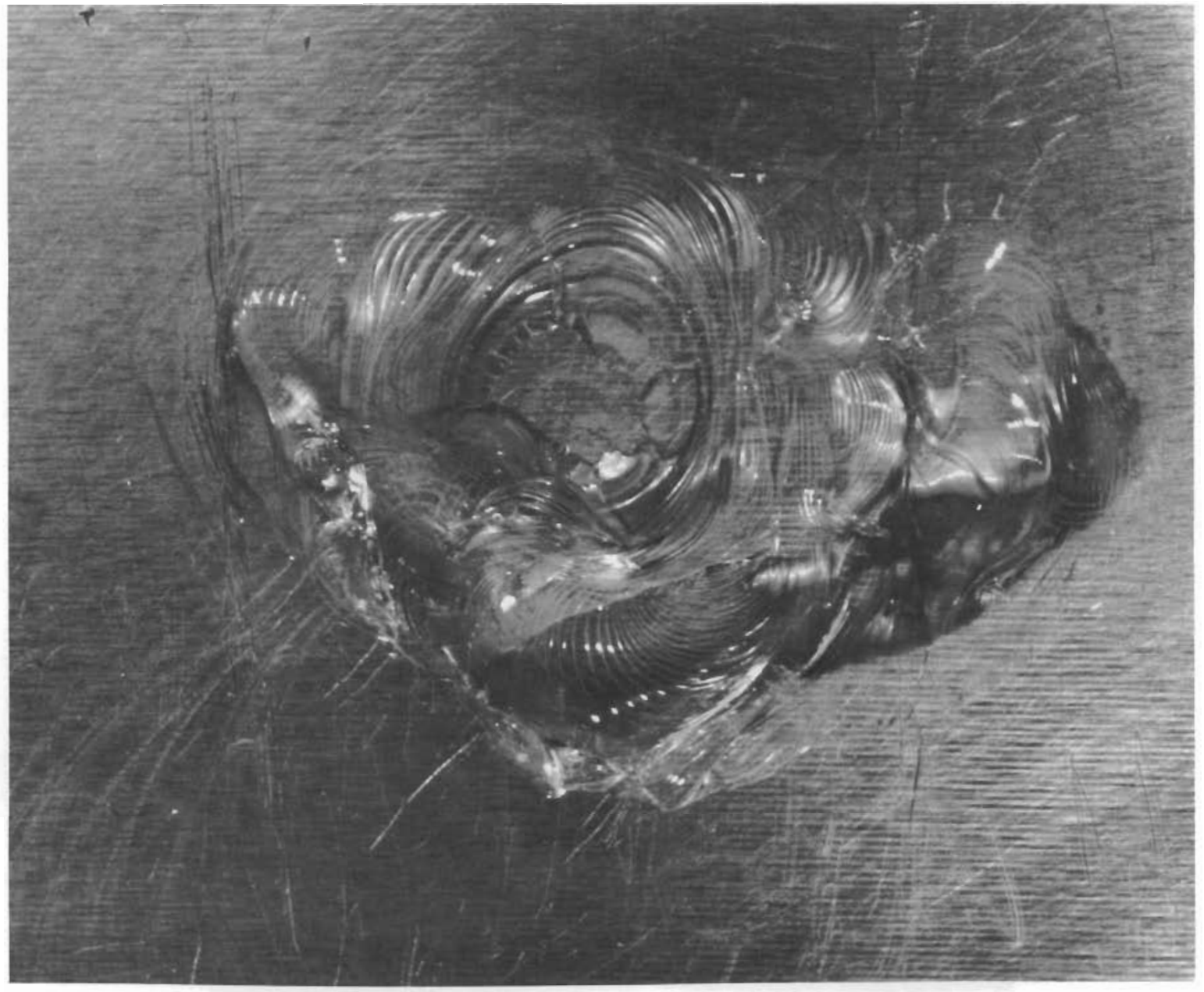

FIGURE 8 . Fracture produced in $1 / 4$ inch plate glass by $300 \mathrm{kHz}$ ultrasound.

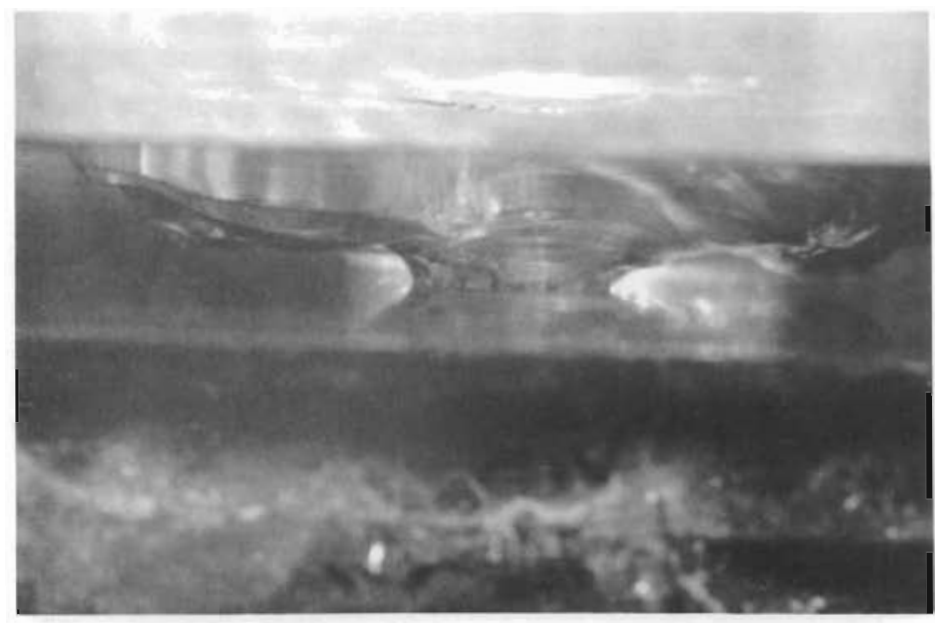

FIGURE 9. Edge view of fracture shown in Figure 8. 


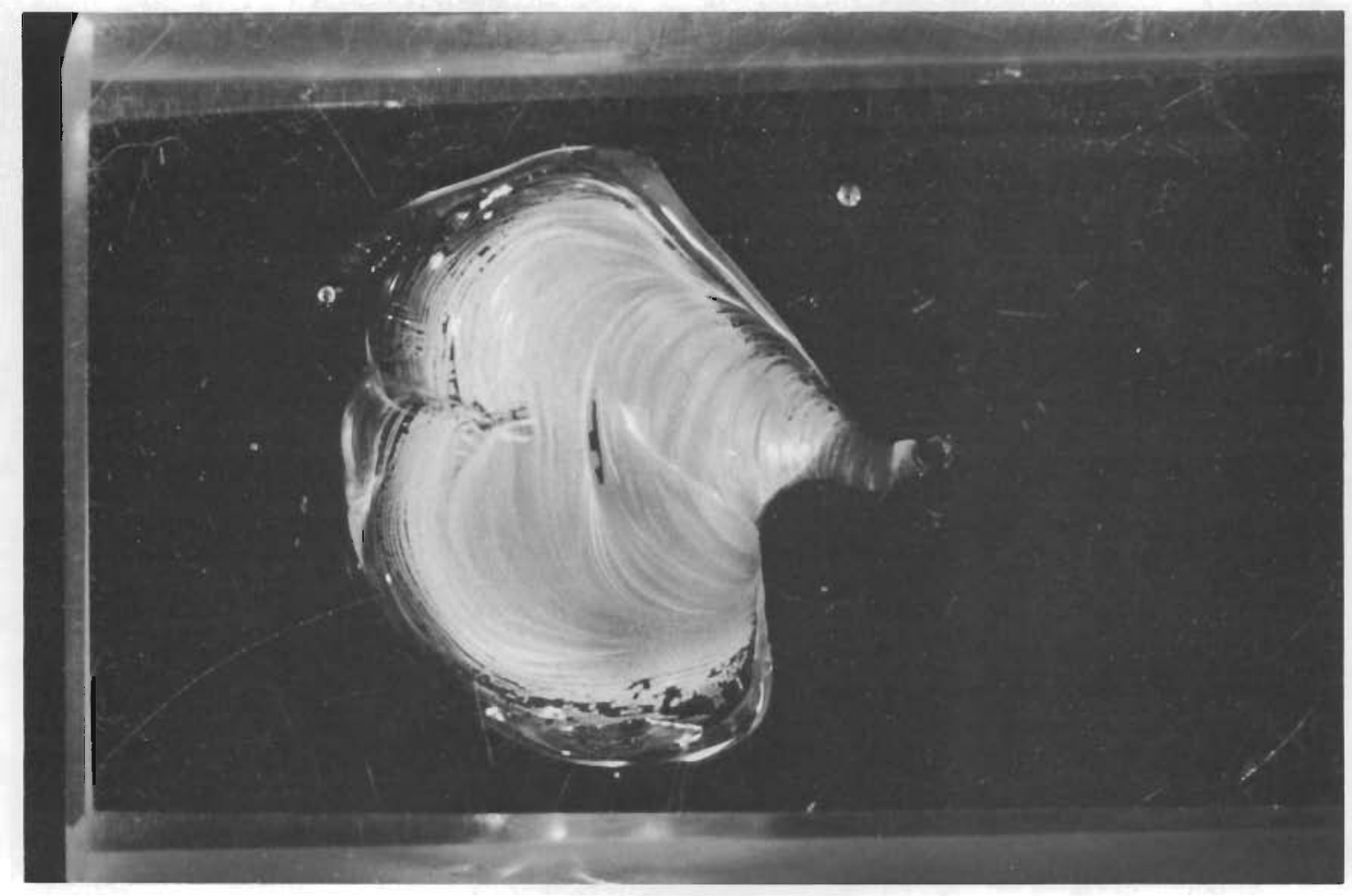

FIGURE 10. Fracture of fused quartz produced by $300 \mathrm{kHz} \mathrm{ultrasound.}$

A fourth demonstration indicates a new and important test method, that of thin film bond strength measurement. A.002 in. film of copper was vapor deposited on a 2. by 2., .25 in. thick steel plate and then insonified using the $300 \mathrm{kHz}$ transducer. The results are shown in Figure 11. A major portion of the area was selectively unbonded giving an orange peel appearance. The central area was completely unbonded and blasted off the substrate. Figure 12 is a $40 x$ enlargement of the central area showing tearing and displacement of the film. The initial bond strength of this film was considered to be as good as could be produced by the vapor deposition technique.

Two other experiments were conducted to further demonstrate this method. A steel substrate was cleaned by the normal procedure and a sma11 area was then contaminated by wiping it with a minute amount of vacuum grease. A.005 in. copper film was then deposited on the substrate. 


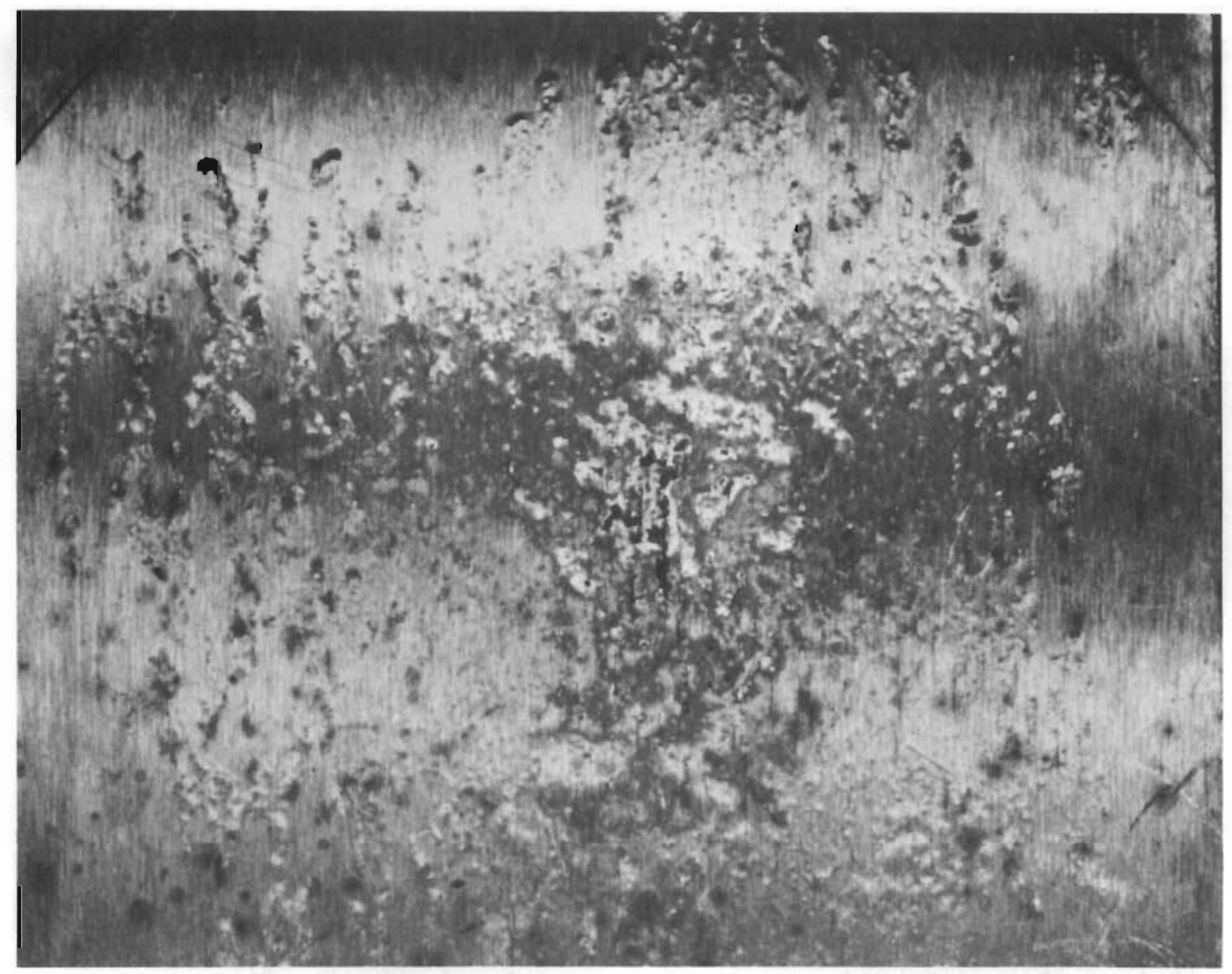

FIGURE 11. Unbonds produced between a .002 in. copper, vapor deposited, film and the steel substrate by $300 \mathrm{kHz}$ ultrasound.

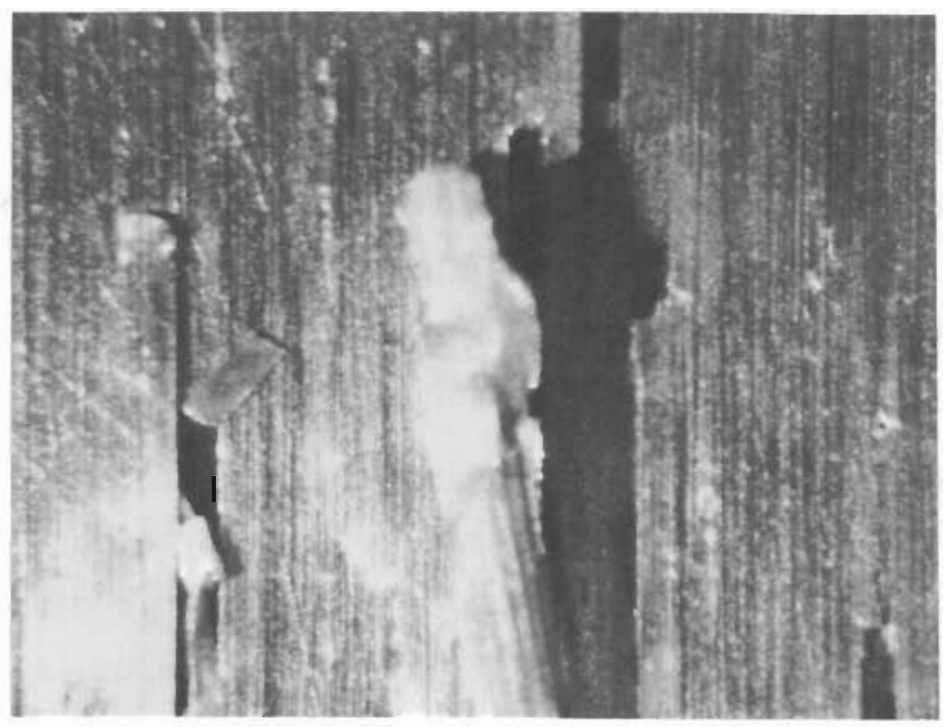

FIGURE 12. Forty $X$ enlargement of the central damage area shown in Figure 11 . 
The resulting film had a normal appearance and could not be 1 ifted or rubbed off. On insonification the contaminated area was immediately and completely removed. In the second test .002 in. of chrome was deposited on glass and steel substrates. The strength of this film was considered to be very high since it could not be lifted or scratched using a very sharp knife. On insonification the film on the glass was almost totally removed while the steel sample remained intact. Figure 13 is a photograph of a portion of the glass sample, the dark areas indicate the remaining chrome film.

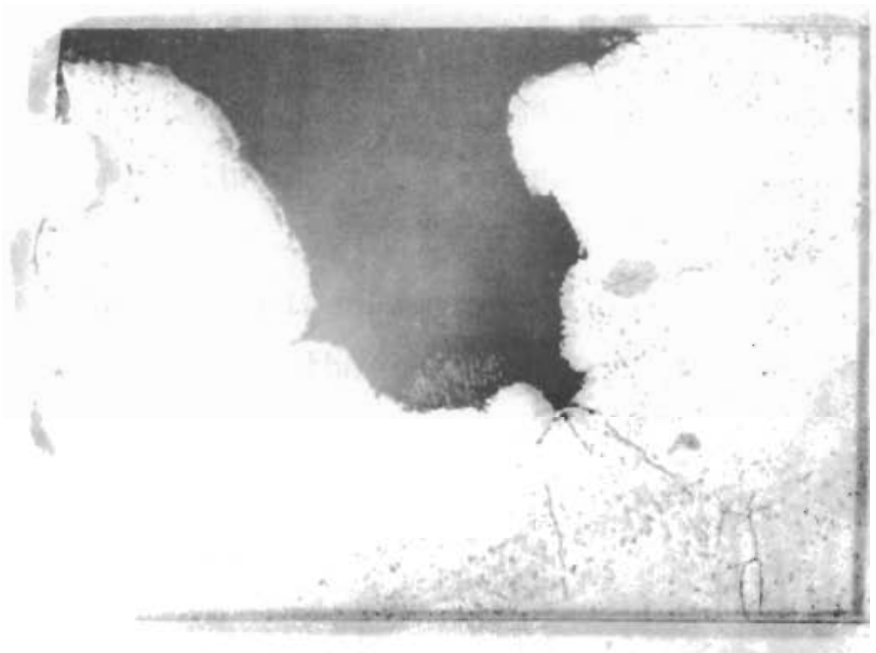

Figure 13. Vapor deposited Nickel film .002 in. thick on a glass substrate partially removed by insonification at $300 \mathrm{kHz}$.

Tests were also performed on a series of sputtered samples which have bond strengths approaching material strengths. None of these samples were damaged by the ultrasonic energy.

The principal goal of this program has been to develop a method for measuring the strength of diffusion bonds. It would have been desirable to test diffusion bonds of various strength, however, the development of a procedure for producing such bonds was considered beyond the scope of this limited program. We therefore attempted to simulate these conditions using optically flat gage blocks under pressure. 
The system configuration is as shown in Figure 2. A .250 in. gage block was epoxy bonded to the transducer and a second block was then wrung on to the first until it could not be moved by hand pressure. The assembly was then placed in a laboratory hydraulic press. The high frequency interrogating transducer was then placed directly above the focal point and the reflected signal monitored as a function of the applied pressure and the ultrasonic intensity.

The first test performed utilized a $10 \mathrm{MHz}$ shear interrogating transducer, both blocks were 1/4 thick, and a clamping pressure of 1,000 psi was used. The photographs of Figure 14 show the influence of the acoustic pressure on the signal transmitted thru and reflected from the interface. Figure 14-A is the signal received at 1000 psi before and after the application of the high power $300 \mathrm{kHz}$ sound. The signal at $1 \mathrm{~cm}$ is the interface reflection and the next signal is reflection from the back surface of the second block in combination with the second multiple of the interface reflection. Figure 14-B indicates the influence of the $20 \%$ of maximum power from the $300 \mathrm{kHz}$ transducer, the interface signal increased and the transmitted energy reflected from the back surface decreased indicating an unbond. The bond was re-established after the acoustic power was turned off yielding a response identical to the initial condition. Similar results were obtained at pressures up to 15,000 psi, however, the high power ultrasound destroyed the shear transducer before the results could be recorded.

The second demonstration utilized a $15 \mathrm{MHz}$ longitudinal transducer and a .250 inch block bonded to the transducer with a .800 in. block wrung on top of it. A clamping pressure of 15,000 psi was used in this test. Figure 15-A is the initial response, (before application of high power sound). The response shown in Figure $15-\mathrm{A}$ at the $2.5 \mathrm{~cm}$ position is the interface. The next signal is the transmitted back surface reflection .25 in. from the interface. The response in Figure 15-B indicates the bond has been separated as the reflected signal increased and the transmitted signal decreased. After termination of power ultrasound the bond is re-established as indicated in Figure 15-C. The $15 \mathrm{MHz}$ was also destroyed shortly after the completion of this test. 

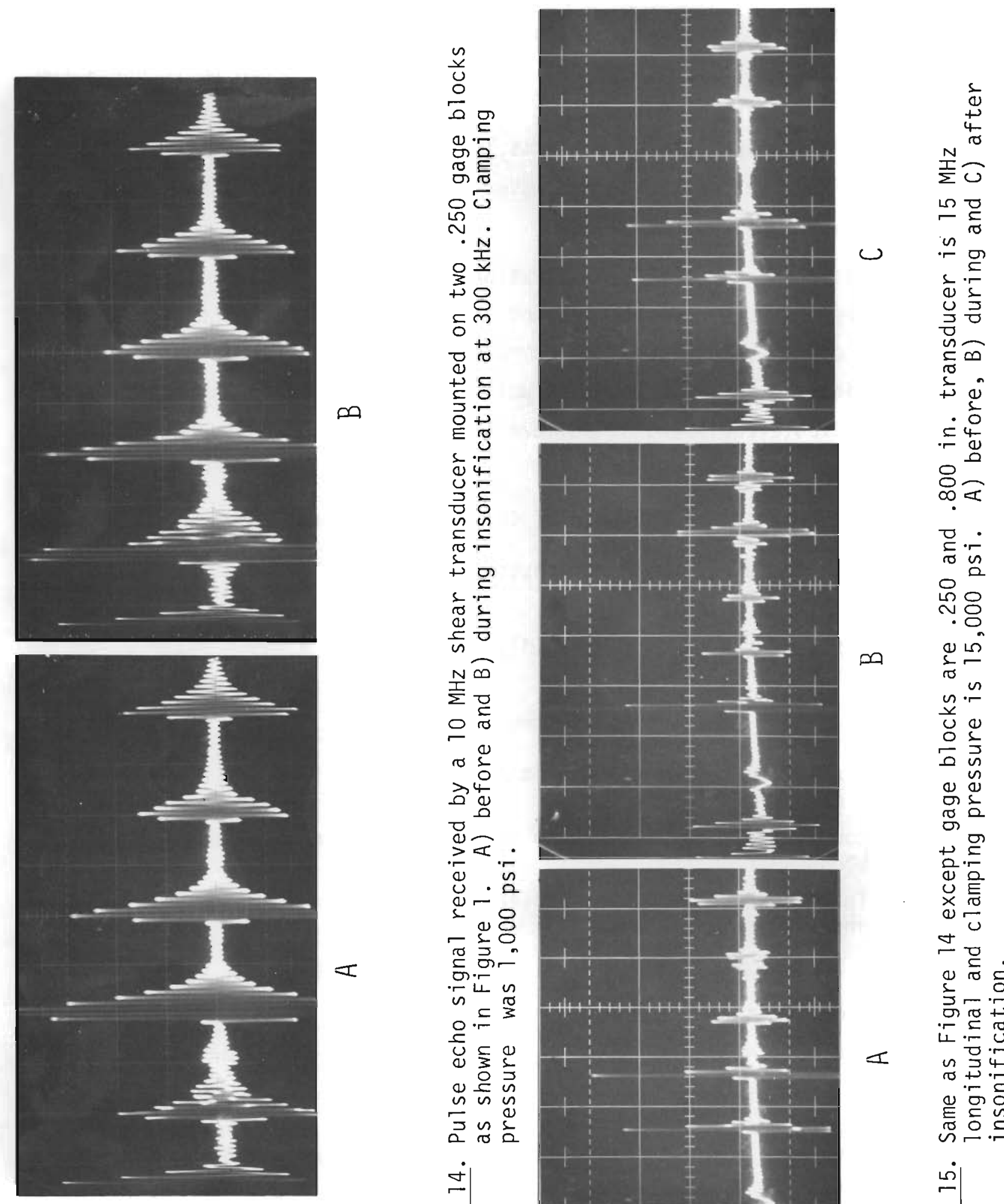

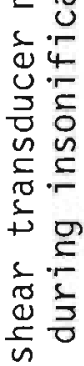

๙

Nㅜㄹ

$\circ$ స

तs

궁

可

过.

\&

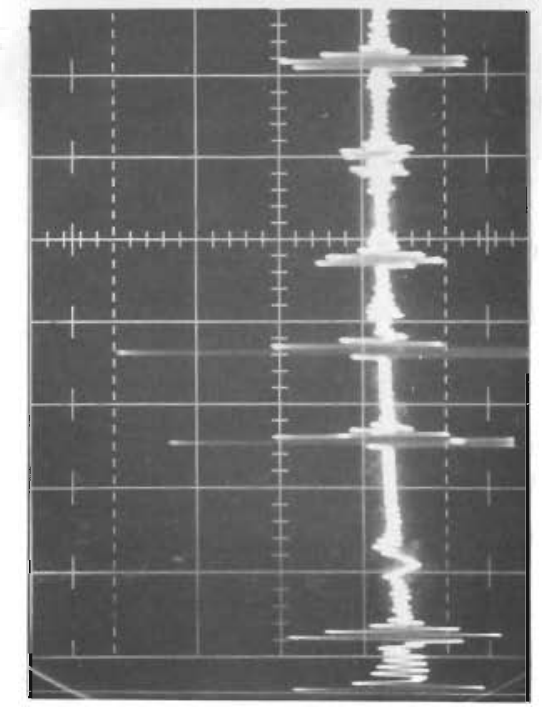

융ㅇㅇ

용

๑ 0 เ

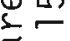

西

离

¿

ก ป

व

os

品

$+9$

足.

过

ब

$\overline{5}$

끋

.5口让

in $=\frac{\pi}{3}$

$0 .{ }^{2}$

울

पे

约

(1) 更

$=$

నᄄ口

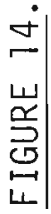

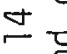

0 등

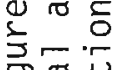

宁它

4.0

$1 \quad n$

$\pi+$

등

है

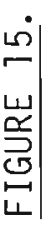


The short life expectancy of the high frequency interrogating transducers can, we believe, be resolved. One solution would be to use a two material coupling member where the interface between the two materials is at an angle which totally reflects longitudinal waves but transmit shear waves. The interrogating shear waves could then be separated from the high power longitudinal waves.

Based on the above demonstration we believe that this technique is a highly feasible approach to bond strength testing. We believe this test method could be developed to accurately measure the bond strength of diffusion and adhesive bonds as well as the bond strength of thin films. With suitable equipment we believe that bond strength approaching 20,000 psi could be measured.

The principle advantages of this technique are:

- Acceptable parts are not destroyed

- Samples are tested in situ

- Tests can be performed rapidly (relative to existing destructive tests).

The limitations of the system are:

- Maximum testable strength is limited to the power produced by the transducer

- Coupling of sound energy to the sample by pressure and/or epoxy bonds is required

- The transducer must be adapted to or designed for each particular application.

A further factor, not considered as a limitation but rather a requirement, is the need for accurate calibration of the transducer power output.

\section{RECOMMENDATIONS FOR FURTHER DEVELOPMENT}

The key element to accurate performance of this test system is the calibration of transducer power output. We would apply the laser optical techniques described in references (2) (3) which have the capabilities of accurately measuring the displacement amplitude of these transducers. 
To further increase the power capabilities of the transducers we would:

1. Select a PZT material with highest possible $d_{33}$.

2. Optimize the transducer configuration for maximum focal point power.

3. Select most suitable cone material for the intended application.

4. Perform suitable electrical impedance matching to optimize power transfer.

The development of more suitable coupling techniques would greatly speed the application of this test. The use of epoxy bonds at the trans ducer sample interface requires 5 to 10 minutes for each test. The pressure at the transducer sample interface is less than the pressure at the focal point. This difference is estimated to be between $1 / 2$ and $1 / 5$ of the focal point pressure due to the larger area and the fact that waves at this interface are not in phase as a result of their different path lengths. If the samples are pressed against the transducer face with a bias pressure of for example 5,000 psi, net tensile pressures of 10,000 to 25,000 psi could be generated at the focal point depending on the focal length, included angle and power capability of the transducer. A viscous liquid couplant would also be used between the sample and the transducer.

This development program would be directed toward the testing of diffusion bonds in candidate materials. Tests would be performed and procedures developed for testing samples of the desired configuration and strengths. 


\section{APPENDIX A}

CALCULATED ACOUSTIC TRANSDUCER OUTPUT

In this appendix we shall attempt to establish, by calculations, a meaningful estimate of the Acoustic pressure generated by our $300 \mathrm{kHz}$ transducer at its focal point. It should be remembered that this is only an approximation and should be considered as an upper limit of the expected acoustic energy output. The calculations shown here are modeled after those of Kraütkramer (1) and Blitz. (4)

The strain ${ }^{\left(\varepsilon_{33}\right)}$ produced on a piezoelectric element is given by

$$
\left(\varepsilon_{33}=d_{33} E\right)
$$

where $d_{33}$ is the piezoelectric modulus and $E$ is the applied electric field, which is equal to the applied voltage divided by the thickness of the element. This equation is valid only for the case of an element freely vibrating in air at some frequency greatly different from the resonant frequency.

In our case the transducer is air loaded on the back side and rigidly attached to steel on the front side. The damping factor for this case is

$$
\delta=\frac{\left(z_{0}+z_{1}\right)^{2}\left(z_{0}+z_{2}\right)^{2}}{\left(z_{0}-z_{1}\right) 2\left(z_{0}-z_{2}\right)^{2}}
$$

where $z_{0}, z_{1}$ and $z_{2}$ are the acoustic impedances of the element, backing member and coupling cone respectively. The values for these constants are $z_{0}=28 \times 10^{6}, z \approx 0$ and $z_{2}=45 \times \frac{10^{6} \mathrm{~kg}}{\mathrm{~m}^{2} \mathrm{sec}}$.

The damping factor for this case is then 18.4 and the $Q$ of the system is given by

$$
Q=\frac{\pi}{\ln \delta}
$$

and is 1.08 for this case. This does not include the influence of internal damping, however, for a low $Q$ system of this type this should 
not be a serious limitation. We therefore expect that the strain produced at resonance will closely approximate that given by equation 1-A.

The $d_{33}$ constant for our transducer material (Channel 5500) is $380 \times 10^{-12}$ meters per volt. The driving voltage measured at the transducer was a maximum of 1250 volts peak and the material thickness was $7.62 \times 10^{-13}$ meters. By equation $1-A$ these constants yield a strain of $62.3 \times 10^{-6}$ meters. The displacements must be continuous across the rigidly bonded transducer-steel interface. The peak strain of a sinusoidal wave is given by

$$
\varepsilon=-k \xi_{0}=-\frac{2 \pi f}{c} \xi_{0}
$$

where $\xi_{0}$ is the displacement and since the displacement across a boundary is continuous the strain produced in the second material is

$$
\varepsilon_{2}=\varepsilon_{1} \frac{c_{1}}{c_{2}} .
$$

In our case the ratio $c_{1} / c_{2}$ is .635 . The strain in the steel is therefore $39.57 \times 10^{-6}$ meters.

The absolute value of the peak pressure produced by a traveling acoustic wave is given by

$$
P=\rho c^{2} \varepsilon
$$

For steel with a density of $7.8 \times 10^{3} \mathrm{~kg} / \mathrm{m}^{3}$ and a velocity of $5.8 \times 10^{3} \mathrm{~m} / \mathrm{sec}$ this yields an acoustic pressure of $10.38 \times 10^{6} \mathrm{~N} / \mathrm{m}^{2}$.

If one could assume that all of this energy could be geometrically focused at the focal point of the transducer we could achieve infinite pressures, this, however, is not the case. We must therefore consider the influences of diffraction and interference from a finite size transducer. The pressure at the focal point of a spherically focused 
transducer is given by

(1)

$$
p_{\text {foc }}=p_{1} \frac{A}{f \lambda}
$$

where $p_{0}$ is the mean acoustic pressure i.e., the pressure at the transducer face in the absence of interference affects, $A$ is the area of the transducer, $f$ is the focal length and $\lambda$ is the wavelength. In our case $A=15.8 \times 10^{-3} \mathrm{~m}^{2}, f=70.99 \times 10^{-3} \mathrm{~m}, \lambda=19.45 \times 10^{-3} \mathrm{~m}$ which yields by Equ. 7-A an acoustic pressure at the focal point of $121 . \times 10^{6} \mathrm{~N} / \mathrm{m}^{2}$ which is equivalent to a pressure of $17,580 \mathrm{psi}$.

We have thus far ignored the influence of the epoxy bonds at the transducer-cone and cone to test piece interfaces. The transmitted intensity of an ultrasonic wave thru two solids separated by a thin layer of a third material is given by (4)

$$
I_{t}=\frac{4 z_{1} z_{2}}{\left(z_{1}+z_{2}\right)^{2} \cos ^{2} k^{\prime} t+\left(z^{\prime}+z_{1}+z_{2} / z^{\prime}\right)^{2} \sin ^{2} k^{\prime} t} \cdot \text { 8-A }
$$

$z_{1}$ and $z_{2}$ are the acoustic impedances of solids 1 and 2 while $z^{-} k^{-}$and $t$ refer to the impedance, wave number and thickness of the intermediate material. This equation approaches $I_{t}$ for two materials as $k^{-} t$ approaches zero. In our case for epoxy with a thickness of .001 in. or $2.54 \times 10^{-5} \mathrm{~m}$ $k^{\prime} t$ is $2 \pi \times 2.8 \times 10^{-3}$ and $\cos ^{2} k^{\prime} t=.99969$ and $\sin ^{2} k^{\prime} t=3.09 \times 10^{-4}$. The influence of the epoxy bonds are therefore negligable for thin layers at this frequency. Higher frequencies and thicker bonds could, however, have a pronounced affect on the transmitted intensity. 


\section{REFERENCES}

1. J. Kraütkramer and H. Kraütkramer, Ultrasonic Testing of Materials, Springer-Verlag, New York, 1969.

2. R. L. Whitman, et al., "Acoustic Surface Displacement Measurements on a Wedge-Shaped Transducer Using an Optical Probe Technique", IEEE Transactions on Sonics and Ultrasonics, Vol. SU-15, No. 3, pp. 168-169, July 1968.

3. C. P. Wang, "A Unified Analysis on Laser Doppler Velocimeters," British Journal of Physics E: Scientific Instruments, Volume 5, 1972.

4. J. Blitz, Fundamentals of Ultrasonics, Plenum Press, New York, 2nd Edition, 1967. 
BNWL- 1789

Special Distribution

in Category UC-37

DISTRIBUTION

NO. OF COPIES

OFFSITE

1 AEC Chicago Patent Group

A. A. Churm

3 AEC Technical Information Center

15 Lawrence Livermore Laboratory

R. B. Engle

G. A. Harter

P. T. Hibdon

A. J. Hodges

K. R. Ker (3)

K. C. MacMillan (3)

R. L. Morton

G. M. Taylor

D. R. Walmsley

C. L. Wraith

ONSITE

$1 \quad$ AEC/RL Patent Attorney

R. M. Poteat

1 AEC Richland Operations Office B. J. Melton

56 Battel le-Northwest

F. L. Becker (40)

J. C. Crowe

T. J. Davis

G. J. Dau

H. R. Gardner

S. J. Foreman

A. J. Haverfield

D. D. Hays

G. J. Posakony

R. W. Stewart

Technical Information (5)

Technical Publications (2) 